\title{
Hemodynamically unstable pelvic fracture: A damage control surgical algorithm that fits your reality
}

\section{Trauma pélvico e inestabilidad hemodinámica: Un algoritmo quirúrgico de control de daños que se adapta con su realidad}

\author{
David Mejia", ${ }^{1}$ Michael W. Parra ${ }^{3}$ (D) Carlos A. Ordoñez ${ }^{4,5,6}$ (D) Natalia Padilla ${ }^{7}$ (D) \\ Yaset Caicedo ${ }^{7}$ (D) Salin Pereira Warr ${ }^{8}$ Paula Andrea Jurado-Muñoz ${ }^{2}$ Mauricio \\ Torres $^{9}$ Alfredo Martínez ${ }^{9}$ (D) José Julián Serna ${ }^{4,5,6,10}$ (D) Fernando Rodríguez-Holguín ${ }^{4}$ \\ (D) Alexander Salcedo 4,5,6,10 (D) Alberto García ${ }^{4,5,6}$ (iD) Mauricio Millán ${ }^{6,11}$ (D) Luis Fernando \\ Pino $^{5,10}$ (D) Adolfo González Hadad ${ }^{5,10,12}$ (D) Mario Alain Herrera ${ }^{5,10}$ (D) Ernest E. Moore ${ }^{13}$ (D) \\ ordonezcarlosa@gmail.com, carlos.ordonez@fvl.org.co
}

1 Hospital Pablo Tobon Uribe, Department of Surgery, Medellin, Colombia.2 Universidad de Antioquia, Department of Surgery, Medellin, Colombia. 3 Broward General Level I Trauma Center, Department of Trauma Critical Care, Fort Lauderdale, FL, USA, 4 Fundación Valle del Lili, Department of Surgery, Division of Trauma and Acute Care Surgery, Cali, Colombia. $\mathbf{5}$ Universidad del Valle, Facultad de Salud, Escuela de Medicina, Division of Trauma and Acute Care Surgery, Department of Surgery. Cali, Colombia.6 Universidad Icesi, Cali, Colombia.7 Fundación Valle del Lili, Centro de Investigaciones Clínicas (CIC), Cali, Colombia, 8 Hospital Pablo Tobón Uribe, Grupo de Soporte Nutricional y Pared Abdominal, Medellin, Colombia 9 Fundación Valle del Lili, Department of Orthopedic Surgery, Cali, Colombia.10 Hospital Universitario del Valle, Department of Surgery, Division of Trauma and Acute Care Surgery, Cali, Colombia.11 Fundación Valle del Lili, Department of Surgery, Division of Transplant Surgery, Cali, Colombia.12 Centro Médico Imbanaco, Cali, Colombia.13 University of Colorado, Denver Health Medical Center, Department of Surgery, Denver, CO USA.

\section{Abstract}

Pelvic fractures occur in up to $25 \%$ of all severely injured trauma patients and its mortality is markedly high despite advances in resuscitation and modernization of surgical techniques due to its inherent blood loss and associated extra-pelvic injuries. Pelvic ring volume increases significantly from fractures and/or ligament disruptions which precludes its inherent ability to self-tamponade resulting in accumulation of hemorrhage in the retroperitoneal space which inevitably leads to hemodynamic instability and the lethal diamond. Pelvic hemorrhage is mainly venous $(80 \%)$ from the pre-sacral/pre-peritoneal plexus and the remaining $20 \%$ is of arterial origin (branches of the internal iliac artery). This reality can be altered via a sequential management approach that is tailored to the specific reality of the treating facility which involves a collaborative effort between orthopedic, trauma and intensive care surgeons. We propose two different management algorithms that specifically address the availability of qualified staff and existing infrastructure: one for the fully equipped trauma center and another for the very common limited resource center. 


\section{Conflict of Interest: None}

\section{Acknowledgment:}

For the illustrations and the design of the cover to the Anatomical Draftsman Fabian R. Cabrera P. Professor of the Design Department of the Faculty of Integrated Arts of the Universidad del Valle

\section{Corresponding author:}

Carlos A. Ordonez, MD, FACS. Division of Trauma and Acute Care Surgery, Department of Surgery. Fundación Valle del Lili. Cali, Colombia; Division of Trauma and Acute Care Surgery, Department of Surgery, Universidad del Valle, Cali, Colombia; Universidad Icesi, Cali, Colombia. Email: ordonezcarlosa@ gmail.com, carlos.ordonez@fvl.org.co

\section{Resumen}

Las fracturas de pelvis ocurren en más del $25 \%$ de los pacientes con trauma severo y su mortalidad es alta, a pesar de los avances en la resucitación hemodinámica y las técnicas quirúrgicas. Esta mortalidad se explica por la hemorragia inherente y las lesiones extra pélvicas asociadas, las fracturas o las disrupciones ligamentarias de la pelvis aumentan el volumen del espacio pélvico, y conlleva a que la hemorragia pélvica se acumule en el espacio retroperitoneal. En poco tiempo, esto conduce a la inestabilidad hemodinámica y el rombo de la muerte. La hemorragia pélvica es un $80 \%$ venosa proveniente de los plexos pre-sacro / pre-peritoneal. El restante $20 \%$ es arterial por sangrado de las ramas de la arteria iliaca interna. Esta realidad podría ser cambiada a través de un manejo secuencial enfocado según la disposición de recursos del centro de atención y de un trabajo colaborativo entre ortopedistas, cirujanos de trauma e intensivistas. Este articulo propone dos algoritmos de manejo que están enfocados según la disponibilidad de un equipo calificado e infraestructura existente: uno para un centro de trauma totalmente equipado, y el otro para un centro con recursos limitados.

\section{Remark}

\section{1)Why was this study conducted?}

Pelvic hemorrhage is mainly venous with a high mortality. This reality can be altered via a sequential management approach that is tailored to the specific reality of the treating facility which involves a collaborative effort.

\section{2) What were the most relevant results of the study?}

We propose two different management algorithms that specifically address the availability of qualified staff and existing infrastructure: one for the fully equipped trauma center and another for the very common limited resource center.

\section{3) What do these results contribute?}

The optimal management of pelvic trauma in the hemodynamically unstable patient is controversial and its mortality rate can reach up to $50 \%$. We believe that this reality can potentially be altered via a sequential and organized management approach adapted to the reality of treating facility.

\section{Introduction}

Pelvic fractures occur in up to $25 \%$ of all severely injured trauma patients and its mortality is markedly high despite advances in resuscitation and modernization of surgical techniques due to its inherent blood loss and associated extra-pelvic injuries ${ }^{1-4}$. Pelvic ring volume increases significantly from fractures and/or ligament disruptions which precludes its inherent ability to self-tamponade resulting in accumulation of hemorrhage in the retroperitoneal space which inevitably leads to hemodynamic instability and the lethal diamond. Pelvic hemorrhage is mainly venous $(80 \%)$ from the pre-sacral/pre-peritoneal plexus and the remaining $20 \%$ is of arterial origin (branches of the internal iliac artery) ${ }^{5,6}$. This reality can be altered via a sequential management approach that is tailored to the specific reality of the treating facility which involves a collaborative effort between orthopedic, trauma and intensive care surgeons. We propose two different management algorithms that specifically address the availability of qualified staff and existing infrastructure. 
Hemodynamically unstable pelvic fracture: A damage control surgical algorithm that fits your reality.

This article is a consensus that synthesizes the experience earned during the past 30 years in trauma critical care management of the severely injured patient from the Trauma and Emergency Surgery Group (CTE) of Cali, Colombia which is made up of experts from the University Hospital Fundación Valle del Lili, the University Hospital del Valle "Evaristo García”, the Universidad del Valle and Universidad Icesi, the Asociación Colombiana de Cirugia, the Pan-American Trauma Society and the collaboration of international specialists of the United States of America, Europe, Japan, South Africa and Latin America.

\section{Epidemiology}

More than $90 \%$ of patients evaluated in level 1 trauma centers with pelvic injuries are secondary to low-energy incidents. However, 5 to $10 \%$ of these are caused by high impact mechanisms and are associated with ongoing hemorrhage ${ }^{7,8}$. The optimal management of pelvic trauma in the hemodynamically unstable patient is controversial and its mortality rate can reach up to $50 \%$. Pelvic fractures are generally associated with other injuries which include thoracic (21\%), intracranial (17\%), abdominal (8\%), and skeletal (7\%) $)^{4,7}$. An observational study conducted at the Hospital Universitari Parc Taulí in Sabadell, Spain, included 1088 trauma patients. One hundred and fifty-seven had pelvic fractures from blunt trauma, 63 were hemodynamically unstable and $97 \%$ of them had associated injuries. The median injury severity score (ISS) was 15 and the overall mortality reached $18.5 \%{ }^{9}$. A retrospective descriptive study conducted at San Vicente University Hospital Foundation in Medellín specifically studied the morbidity and mortality associated with high-energy orthopedic trauma. In this study, 3\% of 357 patients suffered pelvic trauma secondary to motor vehicle accidents. Although the mortality was statistically low, the long-term functional disability rate significantly influenced the overall work absenteeism and productivity ${ }^{10}$. A similar study in Cali included 220 patients with 351 fractures: 315 long bone, 20 pelvic and 16 vertebral. Ninety one percent (202) had associated abdominal injuries, 90\% (198) thoracic and 84\% (184) intracranial. The mechanism of injury most commonly involved was also motor vehicle accidents $71 \%$ (155) but in contrast, 14\% were by gunshot wounds, $7 \%$ from land mines and $6 \%$ from falls ${ }^{11}$.

\section{Initial approach, diagnosis and surgical management}

\section{Fully equipped trauma center}

Initial management must be directed towards the stabilization of the patient according to the Advanced Trauma Life Support (ATLS) guidelines which include the essential ABC's. Damage control resuscitation (DCR) is initiated followed by a chest/pelvic X-rays and a focused assessment with sonography for trauma (FAST) ${ }^{1,12-14}$. The most widely used radiographic staging system for pelvic ring fractures is the Young and Burgess classification, it takes into account force type, severity, direction and mechanical stability (Figure 1) ${ }^{15}$. The choice between immediate surgical exploration or further extended imaging studies depends on the hemodynamic status of the patient. Those with hemodynamic instability (sustain systolic blood pressure (SBP) $\leq 90 \mathrm{mmHg}$ ) and/or associated surgical intra-abdominal injuries should be transferred immediately to the operating room (OR).

Based on our experience we propose a new algorithm for the management of hemodynamically unstable pelvic fractures in a fully equipped trauma center (Figure 2):

- $\quad$ STEP 1: Attention should be directed towards identifying all immediate life-threatening injuries following the ABCDE mnemonic of ATLS (chest/pelvic x-ray and FAST exam) ${ }^{1,12-}$

14. Both a common femoral vein and artery lines are placed for intravenous access and blood pressure monitoring. An aggressive DCR is initiated via the activation of the institution's massive transfusion protocol (MTP). The patient's pelvic injury is then categorized according to the World Society of Emergency Surgery (WSES) classification (Table 1). This classification includes the type (Young and Burgees), the mechanical and the hemodynamic status of the patient ${ }^{1,15}$. 


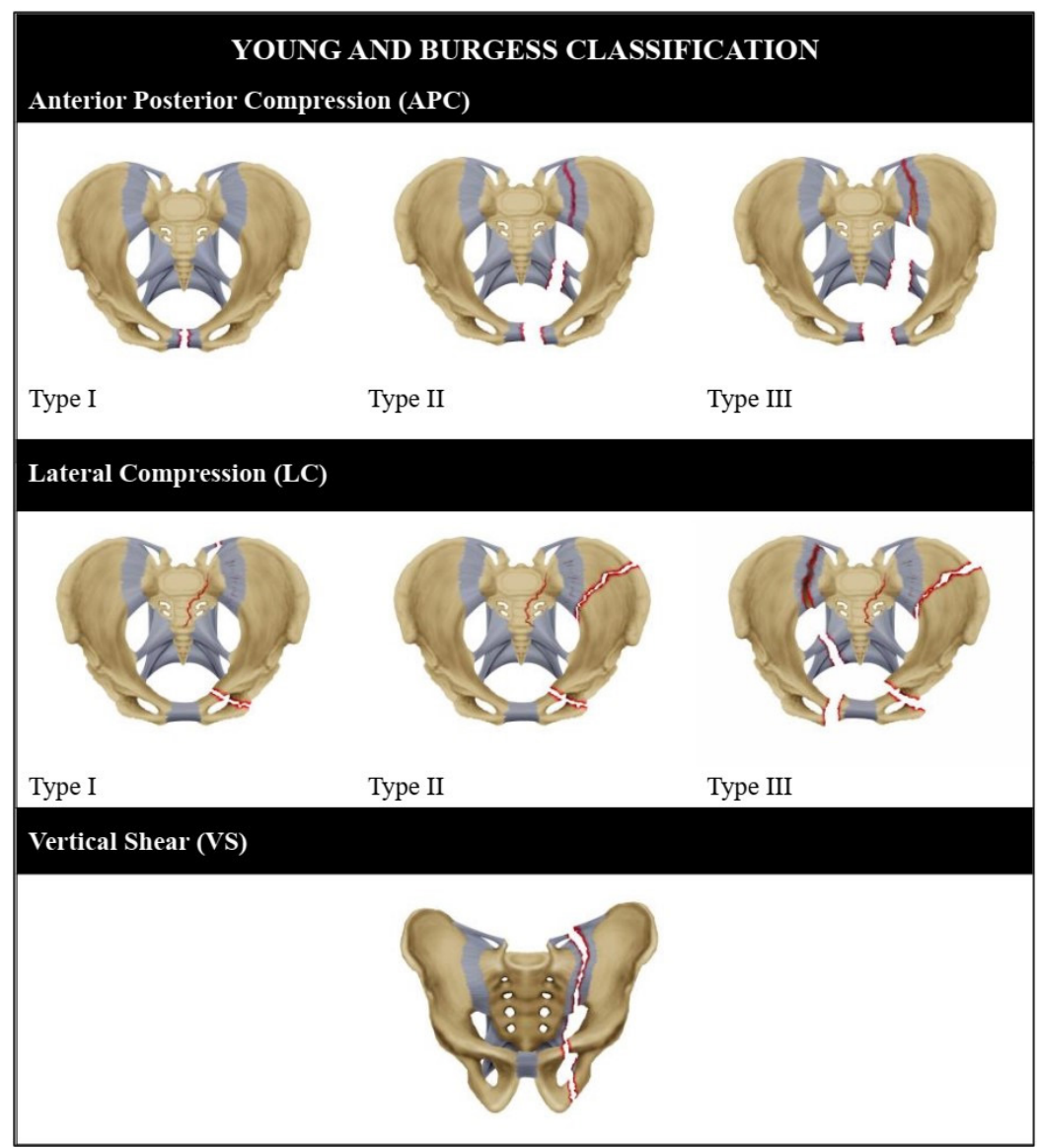

Figure 1. Young and Burgess Classification of Pelvic Ring Injuries [15] Anterior Posterior Compression: I: Symphysis widening $<2.5 \mathrm{~cm}$ II: Symphysis widening $>2.5$. $\mathrm{cm}$. Anterior sacroiliac joint diastasis. Disruption of sacrospinous and sacrotuberous ligaments. III: Sacroiliac dislocation with associated vascular injury. Lateral Compression: I: Compression fractures of the pubic rami (superior pubic ramus and inferior pubic ramus) and ipsilateral anterior sacral ala. II: Rami fracture and ipsilateral posterior ilium fracture dislocation. III: Ipsilateral lateral compression and contralateral anterior posterior compression. Vertical Shear: Posterior and superior directed force.

- $\quad$ STEP 2: The patients with hemodynamic instability related to their pelvic fractures require mechanical stabilization with an external fixation device that is readily available in the Emergency Room (ER)/Trauma Bay. This may be a sheet (pelvic girdle) or a commercial device such as a pelvic binder which exerts a compressive force on the pelvic ring, decreases movement of bone fragments and allows volume reduction ${ }^{1,14}$. If the fracture is vertically displaced (Figure 1), longitudinal traction of the extremity may also be required ${ }^{12}$.

- STEP 3: If the patient is hemodynamically stable or a transient responder, a whole-body computed tomography (WBCT) should be performed to determine the extent of the pelvic fracture and the presence of any other associated injuries ${ }^{16}$. If the patient remains hemodynamically unstable then the common femoral arterial line should be changed over a guidewire to a femoral sheath, followed by placement of a Resuscitative Endovascular Balloon Occlusion of the Aorta (REBOA) in Zone 1 which can be placed either in the ER or operating room.

- STEP 4: If associated intra-abdominal surgical injuries are suspected and/or confirmed by WBCT, FAST and/or physical exam, then the patient should be taken immediately to the OR for exploratory laparotomy and pre-peritoneal pelvic (PPP) packing (Figure 3A/3B). 


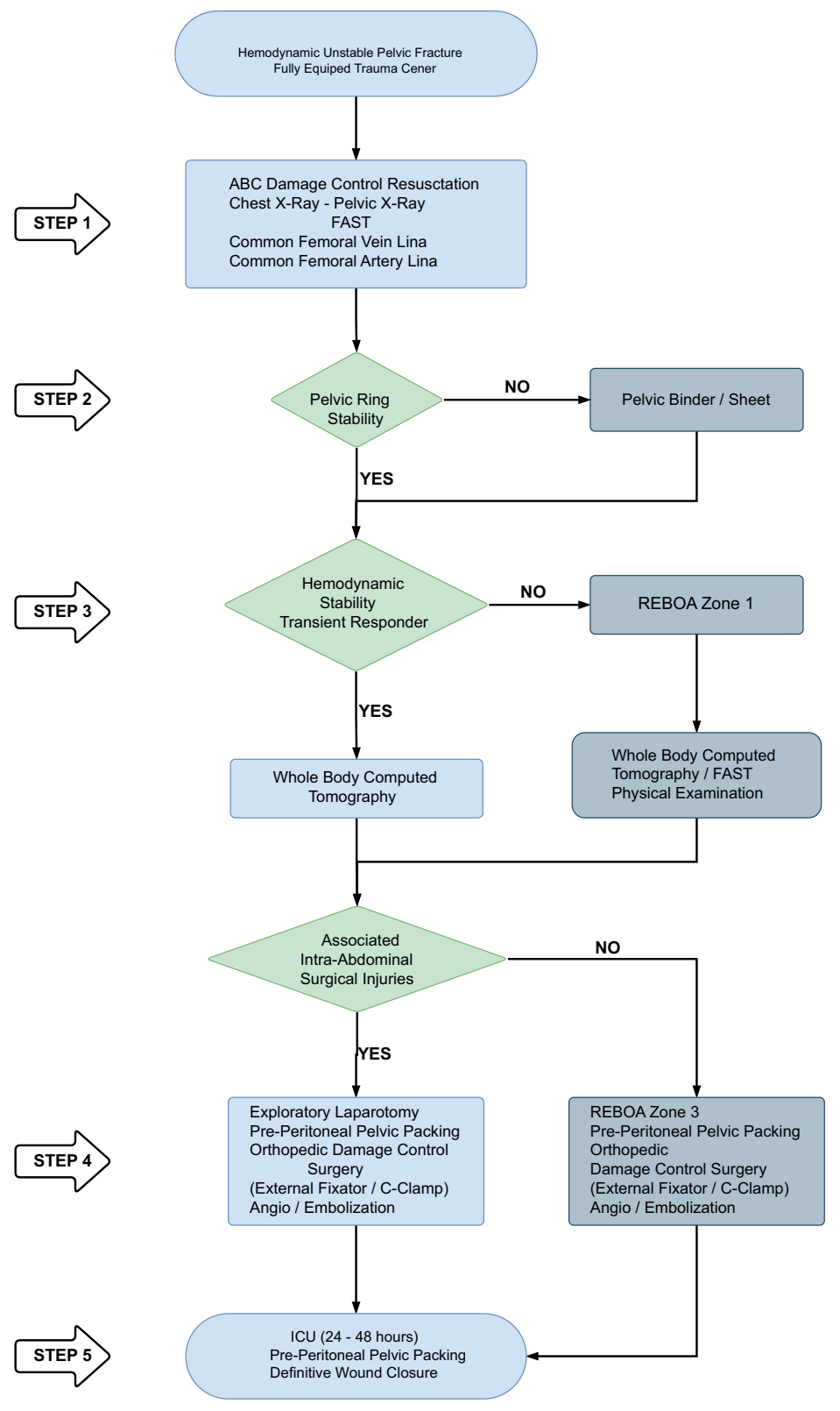

Figure 2 Management Algorithm of Hemodynamic Unstable Pelvic

If the pelvic fracture is unstable, invasive pelvic fixation (external fixator/C-clamp) should be considered, followed by pelvic angiography with embolization of any ongoing arterial bleeding ${ }^{17}$. If associated intra-abdominal surgical injuries are not suspected nor confirmed then the REBOA balloon should be lowered and repositioned to zone 3 , the pelvis should be PPP packed and pelvic angiography with embolization of any ongoing arterial bleeding should be performed ${ }^{18}$.

- $\quad$ STEP 5: The patient should be transferred to the intensive care unit (ICU) after angiography for lethal diamond correction. Once obtained, the patient should be transferred back to the OR for PPP packing removal and definitive wound closure. During this take back, if pelvic hemorrhage persists, then new packing should be reinstated and repeat pelvic angiography with possible embolization should be reconsidered ${ }^{18}$. 
Hemodynamically unstable pelvic fracture: A damage control surgical algorithm that fits your reality.

Table 1. World Journal of Emergency Surgery (WSES) Pelvic Injury Classification ${ }^{19}$

\begin{tabular}{lclll}
\hline & WSES Grade & Young-Burgees Classification & Hemodynamic & Mechanic \\
\hline Minor & I & APC I - LC I & Stable & Stable \\
Moderate & II & APC II/III - LC II/III & Stable & Stable \\
& III & VS - Combined Mechanism & Unstable & Any \\
Severe & IV & Any & Unsle \\
\hline
\end{tabular}

\section{Limited resource center}

Similarly, to a fully equipped trauma center, initial management must be directed towards the stabilization of the patient according to the ATLS guidelines which include the essential ABC's. DCR is initiated followed by a chest/pelvic $\mathrm{x}$-rays and a FAST if available ${ }^{1,12-14}$. The pelvic fracture should be classified following Young and Burgess criteria (Figure 1) ${ }^{15 .}$

We propose a new algorithm for the management of hemodynamically unstable pelvic fractures that fits the reality of limited resources throughout the world (Figure 4):
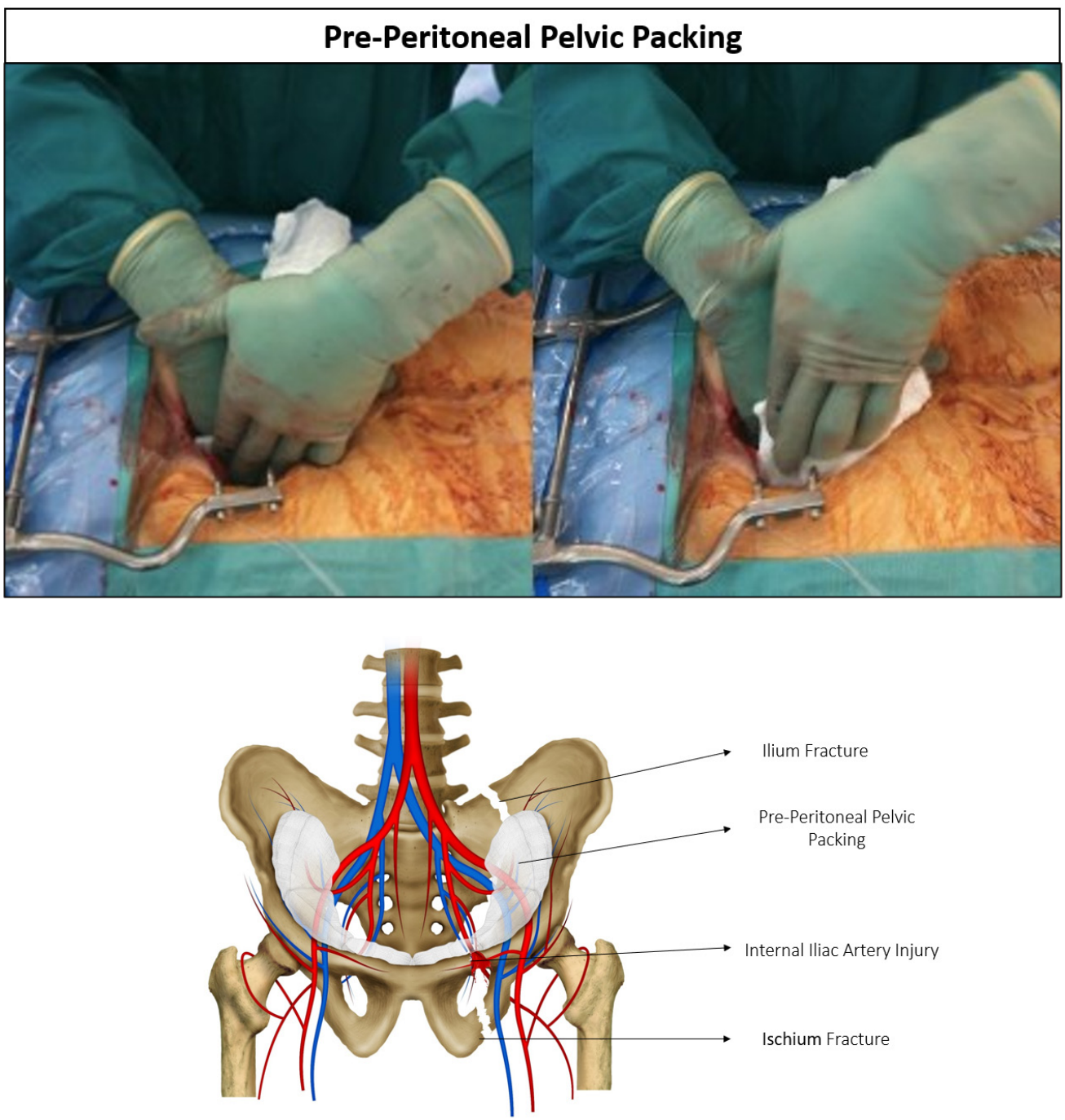

Figure 3. Pre-Peritoneal Pelvic Packing

A: Surgical approach via infraumbilical midline incision. B: Pre-peritoneal pelvic packing C: Pre-peritoneal pelvic packing is controlling the hemorrhage of internal iliac artery injury by the ilium and ischium fracture 


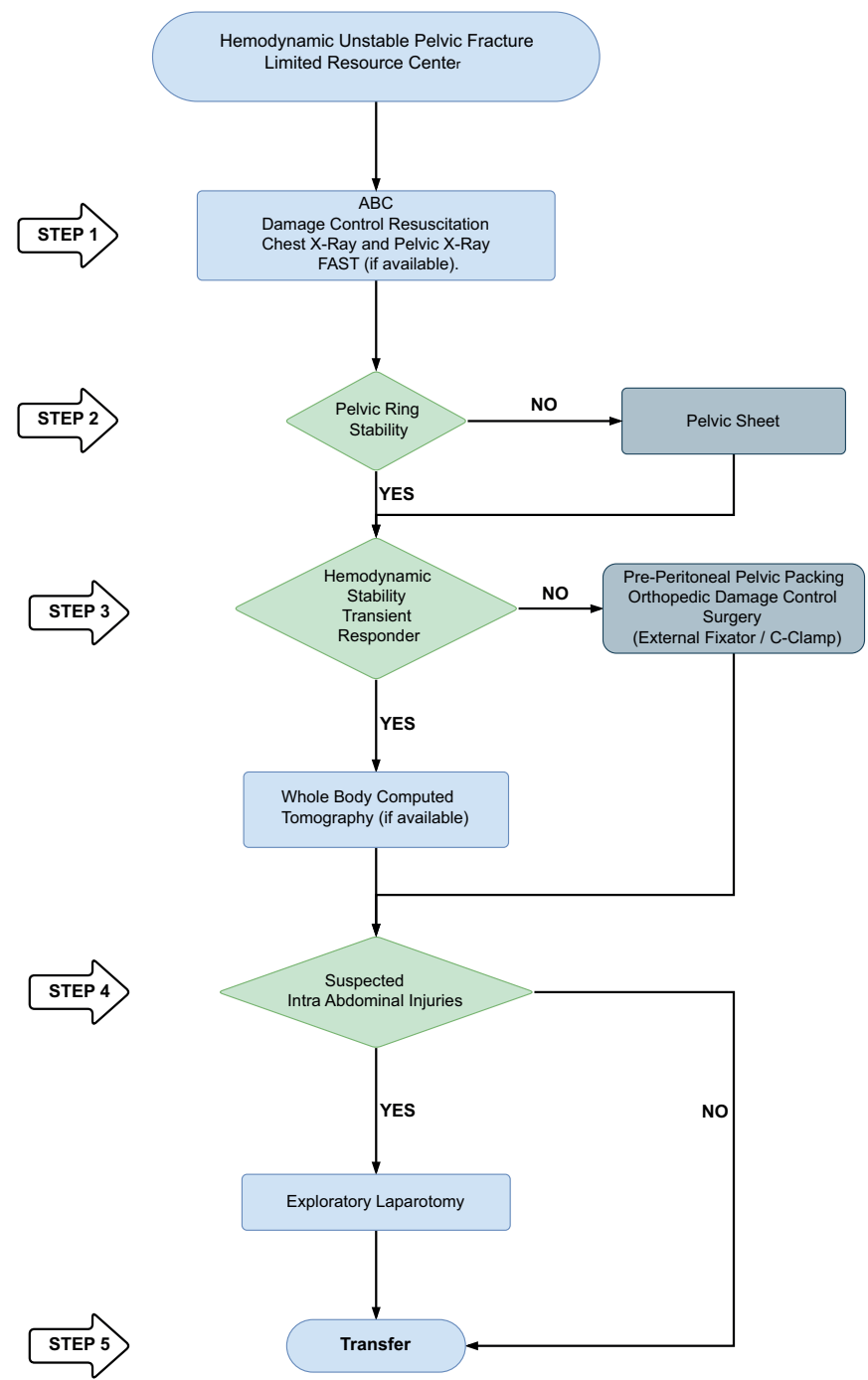

Figure 4. Management Algorithm of Hemodynamic Unstable Pelvic Fractures in Limited Resource Centers

- STEP 1: Attention should be directed towards identifying all immediate life-threatening injuries following the ABCDE mnemonic of ATLS (chest/pelvic x-ray and FAST exam if available) ${ }^{12,14}$. An aggressive DCR is initiated and the patient's pelvic injury is then categorized according to the WSES classification (Table 1) ${ }^{1}$.

- STEP 2: The patients with hemodynamic instability related to their pelvic fractures require mechanical stabilization with an external fixation device that is readily available in the ER. This may be a sheet (pelvic girdle) or a commercial device (if available) such as a pelvic binder which exerts a compressive force on the pelvic ring, decreases movement of bone fragments and allows volume reduction ${ }^{1,14}$. If the fracture is vertically displaced (Figure 1), longitudinal traction of the extremity may also be required ${ }^{12}$.

- STEP 3: If the patient is hemodynamically stable or a transient responder, a WBCT should be performed (if available) to determine the extent of the pelvic fracture and the presence of any other associated injuries ${ }^{16}$. If the patient remains hemodynamically unstable then the patient should be taken immediately to the OR for an infra-umbilical PPP packing, followed by an orthopedic DCS (external fixator/C-clamp) or noninvasive external fixation as indicated per the type of fracture ${ }^{19}$. 
- STEP 4: If associated intra-abdominal surgical injuries are suspected and/or confirmed then a supra-umbilical exploratory laparotomy should follow.

- STEP 5: If the patient required PPP packing, orthopedic DCS and/or exploratory laparotomy then immediate transfer to a referral facility of higher care should be initiated. As well, patients who did not require any DCS procedure should also be transferred to a referral facility of higher care for follow-up pelvic angiography, ICU resuscitation and definitive pelvic fracture management ${ }^{18}$.

\section{Discussion}

Despite advances in trauma critical care, mortality from severe pelvic fractures remains high, with more than a third of deaths secondary to uncontrolled hemorrhage ${ }^{2}$. This has generated the creation of several different management algorithms in North America and Europe that have focused on the hemodynamically unstable severely injured patient with mixed results. The optimal management strategy of these patients remains controversial even in fullyequipped trauma centers and exclude the infrastructure of those with limited resources. The major challenge is the ability to integrate in a sequential and organized fashion all the components, equipment and personnel. For this purpose, we propose a surgical management algorithm that fits the reality of a fully functional level I trauma center and another that addresses the limitations that are common in many centers around the world. The essential components of both algorithms include: DCR, mechanical stabilization, PPP packing, angioembolization and the use of the REBOA (when feasible).

\section{Damage control resuscitation}

DCR seeks to combat metabolic decompensation of the severely injured trauma patient by battling three major fronts: permissive hypotension, hemostatic resuscitation, and DCS. The aim of permissive hypotension is to keep the blood pressure low enough to avoid dislodging a potentially forming soft blood clot at the site of traumatic hemorrhage and/or minimize the blood loss from it but high enough to continue to perfuse vital organs ${ }^{20}$. Hemostatic resuscitation is the volumetric restoration of blood loss via a 1:1:1:1 blood component ratio of packed red blood cells, fresh frozen plasma, platelets and cryoprecipitates ${ }^{21,22}$. Finally, DCS safeguards the trauma patients physiological reserve by controlling the source of surgical bleeding ${ }^{23}$.

\section{Mechanical stabilization}

Simple application of the pelvic binder/sheet has been shown to improve the rotational stability of the pelvis and reduce by up to $60 \%$ the number of overall units of blood required to resuscitate the patient ${ }^{19,24,25}$. The pelvic binder, when compared to the pelvic sheet, has greater effectiveness of hemorrhage control. However, in the setting where a pelvic binder is not readily available as it is the reality of many limited resource centers, then the pelvic sheet should suffice. All non-invasive external pelvic fixation devices should be removed as soon as possible to avoid soft tissue injuries and immediate orthopedic DCS techniques (external fixator/C-clamp) applied according to the appropriate pelvic fracture type in the OR by the orthopedic service, simultaneously as efforts are made by the treating trauma surgeon to control hemorrhage via PPP packing and also angioembolization of the pelvis by the interventional radiologist ${ }^{17,19,26}$. Once hemorrhage is controlled and the patients have been adequately resuscitated in the ICU then plans for definitive invasive pelvic ring reconstruction by the orthopedic service can be considered when indicated.

\section{Pre-peritoneal pelvic (PPP) packing}

The PPP packing is the most important first-line management tool to achieve hemorrhage control in patients who are hemodynamically unstable from severe pelvic fractures due to the fact that $80 \%$ of all pelvic bleeding is venous in origin ${ }^{14,27}$. This technique has gained popularity in recent years because it has been found to be safe and decrease the overall mortality of these 
Hemodynamically unstable pelvic fracture: A damage control surgical algorithm that fits your reality.

patients when combined with other damage control strategies ${ }^{28,29}$. The true advantage of this technique is that it requires minimal specialized equipment and basic surgical training on behalf of the treating physician. For this reason, it is a pillar in both of our proposed algorithms but it does require a follow-up operation between $24-48$ hours for packing removal ${ }^{1730-33}$.

\section{Angioembolization}

Arterial injuries secondary to pelvic trauma have been reported to be up to $20 \%$ in patients with severe unstable ring injuries. Intra-pelvic arterial bleeding is difficult to control with external fixation measures alone, since an adequate tamponade effect is not effectively achievable ${ }^{34}$. For this reason, arterial embolization has gained popularity as one of the techniques used to control bleeding in patients with pelvic fractures with active arterial bleeding ${ }^{18}$. The indications for angioembolization according to WSES are ${ }^{17,28,31,32}$ :

- Control of bleeding in patients with unstable pelvic fractures with arterial sources

- Patients undergoing pelvic angiography with persistent signs of ongoing hemorrhage and in whom extra-pelvic sources of bleeding have been previously ruled out

- Patients with ongoing hemorrhage and/or transfusion requirements after PPP packing

The need for angioembolization following PPP packing has been reported to be between 13 and $20 \%{ }^{35-38}$. However, Totterman et al. ${ }^{39}$, reported that $80 \%$ of patients who underwent PPP packing had positive findings for arterial injury at angiography. That is why in our limited resource center algorithm it is a necessity to always transfer the patient to a higher care facility after the initial resuscitation and packing of the patient ${ }^{29}$.

\section{Resuscitative Balloon Occlusion of the Aorta (REBOA)}

REBOA is an adjuvant technique for patient resuscitation that seeks to redistribute blood flow to vital organs. In patients with pelvic fracture and severe hemodynamic compromise, REBOA should initially be inflated in zone 1 and if associated intra-abdominal surgical injuries are not suspected nor confirmed then the REBOA balloon should be lowered and repositioned to zone $3^{40}$. The 2019 preliminary report of the Aortic Balloon Occlusion Trauma Registry revealed that REBOA when combined with other invasive procedures, improved overall survival of the severely injured pelvic trauma patient ${ }^{41,42}$. To this end, we have included the use of this innovative tool in our algorithm of the fully equipped trauma center but we realize that many limited resource centers do not count with this technology. Despite not having a REBOA, appropriate management and surgical hemorrhage control can still be achieved in a limited resource center, but we reiterate the need for a prompt and efficient transfer of these patients to a higher care facility as early as possible.

\section{Conclusion}

The optimal management of pelvic trauma in the hemodynamically unstable patient is controversial and its mortality rate can reach up to $50 \%$. We believe that this reality can potentially be altered via a sequential and organized management approach adapted to the reality of treating facility. For this reason, we propose two different management algorithms that specifically address the availability of qualified staff and existing infrastructure: one for the fully equipped trauma center and another for the very common limited resource center.

\section{References}

1. Coccolini F, Stahel PF, Montori G, Biffl W, Horer TM, Catena F, et al. Pelvic trauma: WSES classification and guidelines. World J Emerg Surg. 2017; 12:1-18. Doi: 10.1186/s13017-017-0117-6. 
Hemodynamically unstable pelvic fracture: A damage control surgical algorithm that fits your reality.

2. Parry JA, Smith WR, Moore EE, Burlew CCC, Mauffrey C. The past, present, and future management of hemodynamic instability in patients with unstable pelvic ring injuries. Injury. 2020; S0020-1383(20)30176-5. doi: 10.1016/j.injury.2020.02.101.

3. Lewis RH, Sharpe JP, Berning B, Fabian TC, Croce MA, Magnotti LJ. Impact of a simplified management algorithm on outcome following exsanguinating pelvic fractures: A 10-year experience. J Trauma Acute Care Surg. 2019; 86:658-63. Doi: 10.1097/TA.0000000000002162.

4. Hernández L, Bru A. Fracturas Pélvicas: una visión moderna. Rev Española Cirugía Osteoartic. 2015; 50: 39-48.

5. Lee HJ, No HK, Choi NJ, Sun HW, Lee JS, Jung YJ, et al. The size of pelvic hematoma can be a predictive factor for angioembolization in hemodynamically unstable pelvic trauma. Ann Surg Treat Res. 2020;98:146-52. Doi: 10.4174/astr.2020.98.3.146.

6. Gordon WT, Fleming ME, Johnson AE, Gurney J, Shackelford S, Stockinger ZT. Pelvic fracture care. Mil Med. 2018;183:115-7. Doi: 10.1093/milmed/usy111.

7. Manuel L, Núñez G. Trauma pélvico devastante. Cir Gen. 2013;35:31-3.

8. Hermans E, Biert J, Edwards MJR. Epidemiology of Pelvic Ring Fractures in a Level 1 Trauma Center in the Netherlands. Hip Pelvis. 2017;29:253. Doi: 10.5371/hp.2017.29.4.253.

9. Burlew CC, Moore EE, Stahel PF, Geddes AE, Wagenaar AE, Pieracci FM, et al. Preperitoneal pelvic packing reduces mortality in patients with life-threatening hemorrhage due to unstable pelvic fractures. J Trauma Acute Care Surg. 2017;82:233-42. Doi: 10.1016/j.physbeh.2017.03.040.

10. Montmany S, Rebasa P, Luna A, Hidalgo JM, Cánovas G, Navarro S. Origen de la hemorragia en pacientes politraumatizados con fractura de pelvis e inestabilidad hemodinámica. Cir Esp. 2015;93:450-4. Doi: 10.1016/j. ciresp.2015.01.011.

11. Guerra J, Posada Upegui JC, Giraldo Salazar OL. Morbimortalidad en trauma ortopédico de alta energía: estudio descriptivo retrospectivo. Rev Fac Nac Salud Pública. 2018;36:28-36. Doi: 10.17533/udea.rfnsp. v36n2a05.

12. Martínez-Rondanelli A, Uribe JP, Escobar SS, Henao J, Ríos JA, Martínez-Cano JP. Control de daño y estabilización temprana definitiva en el tratamiento del paciente politraumatizado. Rev Colomb Ortop y Traumatol. 2018;32:152-60. Doi: 10.1016/j.rccot.2017.11.009.

13. American College of Surgeons. Advanced trauma life support (ATLS). 10th Edition. Chicago: American College of Surgeons; 2018. Doi: 10.1111/j.1365-2044.1993.tb07026.x.

14. Pape H-C, Peitzman AB, Rotondo MF, Giannoudis PV. Damage control management in the polytrauma patient: An Evolving Comprehensive Team Approach. Springer International Publishing; 2018.

15. Moore EE, Feliciano DV, Mattox KL. Trauma. McGraw-Hill Education; 2017.

16. Alton TB, Gee AO. Classifications in brief: Young and Burgess classification of pelvic ring injuries. Clin Orthop Relat Res. 2014;472:2338-42. Doi: 10.1007/s11999-014-3693-8.

17. Ordoñez CA, Herrera-Escobar JP, Parra MW, Rodriguez-Ossa PA, Mejia DA, Sanchez Al, et al. Computed tomography in hemodynamically unstable severely injured blunt and penetrating trauma patients. J. Trauma Acute Care Surg. 2016; 80: 597-603. Doi: 10.1097/TA.0000000000000975.

18. Burlew CC, Moore EE, Smith WR, Johnson JL, Biffl WL, Barnett CC, et al. Preperitoneal pelvic packing/ external fixation with secondary angioembolization: Optimal care for life-threatening hemorrhage from unstable pelvic fractures. J Am Coll Surg. 2011;212:628-35. Doi: 10.1016/j.jamcollsurg.2010.12.020.

19. Papakostidis C, Kanakaris N, Dimitriou R, Giannoudis PV. The role of arterial embolization in controlling 
Hemodynamically unstable pelvic fracture: A damage control surgical algorithm that fits your reality.

pelvic fracture haemorrhage: A systematic review of the literature. Eur J Radiol. 2012;81:897-904. Doi: 10.1016/j.ejrad.2011.02.049.

20. Croce MA, Magnotti LJ, Savage SA, Wood GW, Fabian TC. Emergent Pelvic Fixation in Patients with Exsanguinating Pelvic Fractures. J Am Coll Surg. 2007;204:935-9. Doi: 10.1016/j.jamcollsurg.2007.01.059.

21. Fraser J, Cowell WM. Clinical study of blood pressure in wound conditions. Nat Treat Wound Shock Allied Cond. 1917;70:520-35.

22. Cannon JW, Khan MA, Raja AS, Cohen MJ, Como JJ, Cotton BA, et al. Damage control resuscitation in patients with severe traumatic hemorrhage: A practice management guideline from the Eastern Association for the Surgery of Trauma. J. Trauma Acute Care Surg. 2017; 82: 605-17. Doi: 10.1097/TA.0000000000001333.

23. Holcomb JB, Tilley BC, Baraniuk S, Fox EE, Wade CE, Podbielski JM, et al. Transfusion of plasma, platelets, and red blood cells in a 1:1:1 vs a 1:1:2 ratio and mortality in patients with severe trauma: The PROPPR randomized clinical trial. JAMA. 2015;313:471-82. Doi: 10.1001/jama.2015.12.

24. Ordoñez CA, Pino LF, Badiel M, Sánchez AI, Loaiza J, Ballestas L, et al. Safety of performing a delayed anastomosis during damage control laparotomy in patients with destructive colon injuries. J. Trauma. 2011; 71: 1512-8. Doi: 10.1097/TA.0b013e31823d0691.

25. Egea-Guerrero JJ, Freire-Aragón MD, Serrano-Lázaro A, Quintana-Díaz M. Objetivos y nuevas estrategias de resucitación en el paciente traumatizado grave. Med Intensiva. 2014;38:502-12. Doi: 10.1016/j. medin.2014.06.003.

26. Toth L, King KL, McGrath B, Balogh ZJ. Efficacy and safety of emergency non-invasive pelvic ring stabilisation. Injury. 2012;43:1330-4. Doi: 10.1016/j.injury.2012.05.014.

27. Jowett AJL, Bowyer GW. Pressure characteristics of pelvic binders. Injury. 2007;38:118-21. Doi: 10.1016/j. injury.2006.03.018.

28. Stahel PF, Burlew CC, Moore EE. Current trends in the management of hemodynamically unstable pelvic ring injuries. Curr Opin Crit Care. 2017;23:511-9. Doi: 10.1097/MCC.0000000000000454.

29. Smith WR, Moore EE, Osborn P, Agudelo JF, Morgan SJ, Parekh AA, et al. Retroperitoneal packing as a resuscitation technique for hemodynamically unstable patients with pelvic fractures: Report of two representative cases and a description of technique. J Trauma. 2005;59:1510-4. Doi: 10.1097/01. ta.0000197330.81352.94.

30. Abrassart S, Stern R, Peter R. Unstable pelvic ring injury with hemodynamic instability: What seems the best procedure choice and sequence in the initial management? Orthop Traumatol Surg Res. 2013;99:175-82. Doi: 10.1016/j.otsr.2012.12.014.

31. Li Q, Dong J, Yang Y, Wang G, Wang Y, Liu P, et al. Retroperitoneal packing or angioembolization for haemorrhage control of pelvic fractures - Quasi-randomized clinical trial of 56 haemodynamically unstable patients with Injury Severity Score =33. Injury. 2016;47:395-401. Doi: 10.1016/j.injury.2015.10.008.

32. Chiara O, di Fratta E, Mariani A, Michaela B, Prestini L, Sammartano F, et al. Efficacy of extra-peritoneal pelvic packing in hemodynamically unstable pelvic fractures, a Propensity Score Analysis. World J Emerg Surg. 2016;11:1-8. Doi: 10.1186/s13017-016-0077-2.

33. Monchal T, Hornez E, Coisy M, Bourgouin S, de Roulhac J, Balandraud P. Preperitoneal pelvic packing. J Visc Surg. 2017;154:S57-60. Doi: 10.1016/j.jviscsurg.2017.08.006.

34. Filiberto DM, Fox AD. Preperitoneal pelvic packing: Technique and outcomes. Int J Surg. 2016;33:222-4. Doi: 10.1016/j.jjsu.2016.05.072.

35. Tang J, Shi Z, Hu J, Wu H, Yang C, Le G, et al. Optimal sequence of surgical procedures for hemodynamically unstable patients with pelvic fracture: A network meta-analysis. Am J Emerg Med. 2019;37:571-8. Doi: 10.1016/j.ajem.2018.06.027. 
Hemodynamically unstable pelvic fracture: A damage control surgical algorithm that fits your reality.

36. Suzuki T, Smith WR, Moore EE. Pelvic packing or angiography: Competitive or complementary? Injury. 2009;40:343-53. Doi: 10.1016/j.injury.2008.12.006.

37. Osborn PM, Smith WR, Moore EE, Cothren CC, Morgan SJ, Williams AE, et al. Direct retroperitoneal pelvic packing versus pelvic angiography: A comparison of two management protocols for haemodynamically unstable pelvic fractures. Injury. 2009;40:54-60. Doi: 10.1016/j.injury.2008.08.038.

38. Tai DKC, Li WH, Lee KY, Cheng M, Lee KB, Tang LF, et al. Retroperitoneal pelvic packing in the management of hemodynamically unstable pelvic fractures: A level I trauma center experience. J Trauma. 2011;71:E79-86. Doi: 10.1097/TA.0b013e31820cede0.

39. Halawi MJ. Pelvic ring injuries: Emergency assessment and management. J Clin Orthop Trauma. 2015;6:252-8. Doi: 10.1016/j.jcot.2015.08.002.

40. Ordoñez CA, Manzano-Nunez R, del Valle AM, Rodriguez F, Burbano P, Naranjo MP, et al. Uso actual del balón de resucitación aórtico endovascular (REBOA) en trauma. Rev Colomb Anestesiol. 2017;45:30-8. Doi: 10.1016/j.rca.2017.07.012.

41. Coccolini F, Ceresoli M, McGreevy DT, Sadeghi M, Pirouzram A, Toivola A, et al. Aortic balloon occlusion (REBOA) in pelvic ring injuries: preliminary results of the ABO Trauma Registry. Updates Surg. 72(2):527-536. doi: 10.1007/s13304-020-00735-4.

42. Jarvis S, Kelly M, Mains C, Corrigan C, Patel N, Carrick M, et al. A descriptive survey on the use of resuscitative endovascular balloon occlusion of the aorta (REBOA) for pelvic fractures at US level I trauma centers. Patient Saf Surg. 2019;13:1-9. Doi: 10.1186/s13037-019-0223-3. 